\title{
Efeito de níveis de melão em substituição ao milho moído sobre o desempenho, o consumo e a digestibilidade dos nutrientes em ovinos Morada Nova
}

\author{
Cláudio Adriano Correia de Lima ${ }^{1}$, Guilherme Ferreira da Costa Lima ${ }^{2}$, Roberto Germano \\ Costa $^{3}$, Ariosvaldo Nunes de Medeiros ${ }^{3}$, Emerson Moreira de Aguiar ${ }^{4}$, Valdi de Lima Júnior ${ }^{4}$ \\ ${ }^{1}$ EMPARN/EMATER. \\ 2 EMBRAPA/EMPARN. \\ ${ }^{3}$ Universidade Federal da Paraíba. \\ 4 Universidade Federal do Rio Grande do Norte.
}

RESUMO - Avaliaram-se o desempenho, o consumo e a digestibilidade aparente de componentes nutritivos em 32 ovinos Morada Nova em confinamento, 20 machos não-castrados e 12 fêmeas, recebendo dietas contendo 0, 30, 60 e 100\% de melão em substituição ao milho moído. Os animais tinham em média 6 meses de idade, peso médio inicial de $15 \mathrm{~kg}$ e foram abatidos aos $25 \mathrm{~kg}$. Utilizou-se delineamento experimental inteiramente casualizado, com quatro tratamentos e oito repetições. O consumo de MS apresentou tendência quadrática para ambos os sexos, variando de 769 a 837 g para os machos e de 722 g a $646 \mathrm{~g}$ para as fêmeas. Os consumos de matéria orgânica (MO), proteína bruta (PB), extrato etéreo (EE), fibra em detergente neutro (FDN), nutrientes digestíveis totais (NDT), carboidratos totais (CT) e carboidratos não-fibrosos (CNF) apresentaram comportamento quadrático, refletindo o mesmo comportamento da ingestão da MS. A digestibilidade aparente da MS apresentou tendência linear decrescente. Os coeficientes de digestibilidade aparente de MO, PB, EE, FDN e CT apresentaram comportamento linear crescente com a adição de melão em substituição ao milho moído. O ganho de peso diário com o aumento do nível de melão na dieta foi maior nos machos. A conversão e eficiência alimentar não foram influenciadas pelo aumento do nível de melão na dieta. Os dias de confinamento variaram de 79 a 90 dias. A substituição na dieta do milho moído por melão possibilitou obter desempenho satisfatório em ovinos Morada Nova em confinamento. O nível de 60\% de substituição é o que permite melhor retorno financeiro, entretanto, em níveis superiores a $30 \%$, aumentam os dias de confinamento, elevando a idade ao abate.

Palavras-chave: confinamento, ganho diário, ovinocultura, semiárido, subprodutos agrícolas

\section{Effect of melon in substitution of ground corn on performance, intake, and nutrients digestibility in Morada Nova lambs}

\begin{abstract}
Performance, intake, and nutrients digestibility of 32 Morada Nova confined lambs were evaluated, using diets with increasing levels $(0,30,60,100 \%)$ of melon (Cucumis melo L.) in substitution of corn grain. Animals were about 6 months old, with an average of $15 \mathrm{~kg}$ of initial body weight and slaughtered at $25 \mathrm{~kg}$. They were allocated in a completely randomized design with four treatments and eight replicates. The dry matter intake (DMI) presented a quadratic behavior for both sex, varying from 769 to $837 \mathrm{~g}$ for males, and from 722 to $646 \mathrm{~g}$ for females. Intakes of OM (organic matter), CP (crude protein), EE (ether extract), NDF (neutral detergent fiber), TDN (total digestible nutrients), TCH (total carbohydrate) and NFC (non fiber-carbohydrate) showed a quadratic curve, reflecting the same behavior of DMI. There was a decreasing linear response for the coefficient of apparent digestibility of dry matter (DM). The apparent digestibility coefficients of OM, CP, EE, NDF, and TCH presented an increasing linear response with the addition of melon in substitution of ground corn in the diet. Concerning the average daily gain (ADG) there was a better performance for males compared with females, as the levels of melon increased. Feed efficiency and conversion were not influenced by the treatments. There was an increasing linear effect for the days of confinement, which varied from 79 to 90 . The levels of melon added to the Morada Nova lambs' diets provided reasonable performances. The treatment with $60 \%$ participation of melon shows the best economical return. On the other hand, when the level of melon is above $30 \%$, the days in confinement increase, elevating the slaughter age.
\end{abstract}

Key Words: agricultural byproducts, daily gain, feedlot, semi-arid, sheep husbandry 


\section{Introdução}

A ovinocultura é uma atividade praticada na maioria das propriedades rurais do semiárido, especialmente por pequenos produtores, e desempenha importante função no desenvolvimento socioeconômico e de fixação do homem à terra, principalmente nesta região, onde a agricultura não tem apresentado sustentabilidade econômica, em decorrência das condições edafoclimáticas, que dificultam a produção, inclusive de forragem.

Neste contexto, torna-se evidente a necessidade de suplementação alimentar para a manutenção dos rebanhos no período de estiagem. $\mathrm{O}$ fruto-refugo do melão tem sido uma opção para a suplementação de ruminantes no período de escassez de alimentos no semi-árido do Nordeste, devido à sua disponibilidade na região, e também por ser um alimento rico em carboidratos não-fibrosos e água.

Os estados do Rio Grande do Norte e Ceará produzem 404.068 t de melão, que representam 81,58\% da produção brasileira(AGRIANUAL, 2010). A produção écomercializada na sua totalidade na forma de fruta fresca, que é a forma de consumo mais comum. Os mercados interno nacional, regional e local consomem $70 \%$ da produção e o mercado externo $20 \%$; os $10 \%$ restantes são frutos-refugo. Considerando os altos índices de produtividade alcançados, a quantidade de frutos-refugo pode representar disponibilidade estimada de 34.950 t/ano (Manterola et al., 1992).

O uso de subprodutos agropecuários na alimentação de ruminantes contribui para reduzir a concorrência por grãos entre animais domésticos e a população humana. Entretanto, grande parte dos grãos produzidos é utilizada na alimentação animal, uma vez que a maioria das rações empregadas na alimentação dos animais são constituídas de $40-50 \%$ de grãos. Por outro lado, ocorre a escassez de grãos para consumo humano, principalmente nos países com baixo desenvolvimento (Dhakad et al., 2002).
Objetivou-se com este estudo avaliar o efeito da substituição do milho moído por melão na dieta sobre o desempenho, o consumo de MS e a digestibilidade de alguns componentes nutritivos em ovinos Morada Nova.

\section{Material e Métodos}

O experimento foi conduzido na Estação Experimental de Terras Secas pertencente à Empresa de Pesquisa Agropecuária do Rio Grande do Norte localizada no município de Pedro Avelino. O clima é tropical quente, com 6 a 8 meses secos, e apresenta precipitação média anual de $473 \mathrm{~mm}$. Foram utilizados 32 ovinos da raça Morada Nova, sendo 20 machos e 12 fêmeas (as fêmeas foram sorteadas aleatoriamente três por tratamento) da variedade vermelha, com idade média de 6 meses, com peso inicial médio de $15 \mathrm{~kg}$ e peso vivo ao abate (PVA) de $25 \mathrm{~kg}$. Os animais foram confinados em baias individuais com $1,2 \times 4 \mathrm{~m}$ de dimensão, $2 \mathrm{~m}$ de piso cimentado (coberto com telhas de cerâmica) e $2 \mathrm{~m}$ de chão batido (solário), providas de comedouros, bebedouros e saleiros. Inicialmente, os animais foram pesados, identificados, vermifugados e distribuídos em quatro grupos, cada uma alimentado com uma dieta contendo melão nos níveis 0, 30, 60 ou 100\% de substituição em substituição ao milho moído. As pesagens foram realizadas a cada sete dias até o final da pesquisa.

Utilizou-se a metodologia descrita por Silva \& Queiroz (2002) para determinação do conteúdo de matéria seca (MS), matéria mineral (MM), proteína bruta (PB), extrato etéreo (EE) e lignina em detergente ácido (LDA) dos alimentos e das dietas experimentais (Tabela 1).

Para determinação dos teores de fibra em detergente neutro (FDN) e fibra em detergente ácido (FDA), utilizou-se a metodologia descrita por Van Soest et al. (1991). Os teores de compostos nitrogenados insolúveis em detergente neutro (NIDN) e em detergente ácido (NIDA) foram obtidos nos resíduos da FDN e FDA, mediante o procedimento de micro Kejdahl.

Tabela 1 - Composição química dos ingredientes da dieta, em \% da matéria seca

\begin{tabular}{lccccc}
\hline & \multicolumn{3}{c}{ Ingrediente } \\
\cline { 2 - 6 } & Milho moído & Melão & Farelo de soja & Torta de algodão & Feno de capim-elefante \\
\hline Matéria seca & 89,35 & 7,28 & 89,62 & 94,14 & 89,64 \\
Matéria mineral & 1,38 & 9,30 & 6,95 & 4,92 & 7,49 \\
Matéria orgânica & 98,62 & 90,70 & 93,05 & 95,08 & 92,51 \\
Proteína bruta & 7,67 & 11,58 & 43,46 & 25,84 & 4,28 \\
Extrato etéreo & 3,19 & 7,62 & 3,23 & 9,60 & 7,80 \\
Fibra em detergente neutro & 16,00 & 20,58 & 26,76 & 31,62 & 5,88 \\
Fibra em detergente ácido & 10,01 & 16,68 & 10,73 & 59,64 & 8,46 \\
Carboidratos totais & 87,76 & 69,94 & 46,36 & 5,33 & 8,43 \\
Carboidratos não-fibrosos & 71,76 & 49,36 & 19,60 & 4,18 & 5,26 \\
Lignina & 1,27 & 5,86 & 1,23 & & \\
\hline
\end{tabular}


As rações experimentais (Tabela 2) tinham em média 16\% de proteína bruta (PB) e foram constituídas de feno de capim-elefante e concentrado, composto de farelo de milho, farelo de soja, torta de algodão, melão e mistura mineral. As rações foram formuladas de acordo com as recomendações do NRC (1985). Os frutos de melão utilizados na pesquisa são aqueles descartados na primeira seleção no campo e, depois, na linha de embalagem, quando são avaliados quanto ao aspecto geral e formato.

O fornecimento das rações experimentais foi realizado duas vezes ao dia, às 7 e às 15 h, na forma de ração completa, durante todo período experimental. Os alimentos ofertados e as sobras foram pesados diariamente, para cálculo do consumo voluntário e reajustes da quantidade fornecida, que deveria ser sempre suficiente para proporcionar sobras correspondentes a $10 \%$ do fornecido.

O ensaio da digestibilidade teve duração de sete dias, período em que foram coletadas amostras do alimento, das sobras e das fezes, que foram pesadas, identificadas e armazenadas em freezer para análises posteriores. Em seguida, procedeu-se ao ensaio de desempenho, cuja duração foi de 90 dias. Após o encerramento do ensaio, as sobras foram homogeneizadas para formação de uma amostra composta por animal.

As amostras de fezes foram coletadas diretamente da ampola retal dos animais, duas vezes ao dia, pela manhã e à tarde. Todas as amostras de alimentos, sobras e fezes foram trituradas em moinho de faca tipo Willey, com peneira de crivo de 1,0 mm para posteriores análises.
A produção da matéria seca das fezes (PMSF) foi obtida utilizando-se fibra em detergente ácido indigestível (FDAi) como indicador interno (Berchielli et al., 2000). Para determinação das concentrações de FDAi, amostras dos alimentos, das sobras e das fezes foram pesadas em sacos de polipropileno (tecido de náilon não-resinado, gramatura $100 \mathrm{~g} / \mathrm{m}^{2}$ ) 0,5 g e incubadas no aparelho de digestibilidade “Daisy”II por 144 horas. Após a incubação, as amostras foram submetidas à extração com detergente ácido, cujo resíduo foi considerado FDAi.

Para a estimativa dos carboidratos totais (CT), utilizou-se a equação proposta por Sniffen et al. (1992), CT = 100 (\%PB + \%EE + \%MM) e os teores de carboidratos nãofibrosos (CNF), por sua vez, foram estimados pela diferença entre carboidratos totais e FDN. O consumo de nutrientes digestíveis totais (NDT) foi calculado segundo Sniffen et al. (1992): $\mathrm{cNDT}=(\mathrm{cPB}-\mathrm{PBf})+2,25 *(\mathrm{cEE}-\mathrm{Eef})+(\mathrm{cCT}-\mathrm{CTf})$, de modo que $\mathrm{CPB}$, cEE e cCT significam, respectivamente, consumo de proteína bruta, extrato etéreo e carboidratos totais, enquanto PBf, EEf e CTf referem-se às excreções de PB, EE e CT nas fezes. Os nutrientes digestíveis totais (NDT) foram calculados pela equação proposta por Weiss (1999): $\mathrm{NDT}=\left[\left(\mathrm{DVPB}+\mathrm{DVFDN}+\left(\mathrm{DVAG}^{*} 2,5\right)\right]-7\right.$. A energia metabolizável foi obtida transformando o NDT em energia digestível (ED), por meio da equação ED $=(\mathrm{NDT}) / 100) \times 4,409$, e posteriormente a ED em energia metabalizável pela equação $\mathrm{EM}=\mathrm{ED} \times 0,82$, segundo o NRC (2000).

Foi efetuada análise de variância e de regressão nos dados relativos ao consumo, à digestibilidade de nutrientes

Tabela 2 - Composição percentual e bromatológica das dietas experimentais com diferentes níveis de melão em substituição ao milho moído

\begin{tabular}{|c|c|c|c|c|}
\hline \multirow[t]{2}{*}{ Ingrediente, \% na MS } & \multicolumn{4}{|c|}{ Nível de melão em substituição ao milho moído, \% } \\
\hline & 0 & 30 & 60 & 100 \\
\hline Milho moído & 29,00 & 20,30 & 11,60 & - \\
\hline Melão (fruto) & - & 8,70 & 17,40 & 29,00 \\
\hline Farelo de soja & 26,50 & 25,50 & 24,60 & 23,50 \\
\hline Torta de algodão & 3,0 & 4,0 & 4,90 & 6,00 \\
\hline Feno de capim-elefante & 40,0 & 40,00 & 40,00 & 40,00 \\
\hline Mistura mineral & 1,50 & 1,50 & 1,50 & 1,50 \\
\hline \multicolumn{5}{|l|}{ Composição química } \\
\hline Matéria seca, \% & 89,83 & 82,73 & 75,64 & 66,17 \\
\hline Matéria orgânica, \% & 93,11 & 92,42 & 91,77 & 89,83 \\
\hline Proteína bruta, \% & 16,90 & 16,76 & 16,66 & 16,55 \\
\hline Extrato etéreo, \% & 2,40 & 2,83 & 3,28 & 3,92 \\
\hline Fibra em detergente neutro, \% & 44,91 & 45,58 & 46,23 & 47,06 \\
\hline Fibra em detergente ácido, \% & 26,78 & 27,56 & 28,34 & 29,36 \\
\hline Carboidratos totais, \% & 75,32 & 74,37 & 73,34 & 71,92 \\
\hline Carboidratos não-fibrosos, \% & 30,41 & 28,79 & 27,11 & 24,86 \\
\hline Lignina & 2,49 & 3,07 & 3,46 & 4,37 \\
\hline Matéria mineral, \% & 5,38 & 6,04 & 6,72 & 7,61 \\
\hline Nutrientes digestíveis totais & 72,66 & 66,66 & 60,61 & 55,40 \\
\hline Energia metabolizável, Mcal de EM/kg de MS & 2,60 & 2,53 & 2,45 & 2,35 \\
\hline
\end{tabular}


e ao desempenho dos animais para ambos os sexos. A escolha dos modelos baseou-se na significância dos coeficientes linear e quadrático, por meio do teste $t$ de "Student", a 5\% de probabilidade. O delineamento experimental utilizado foi inteiramente casualizado, com quatro tratamentos e oito repetições.

\section{Resultados e Discussão}

O consumo de MS expresso em g/dia e \%PV apresentou comportamento quadrático com o ponto de máximo de 910 g e 3,50\% respectivamente, para os cordeiros que receberam dietas contendo melão. Lousada Júnior et al. (2005) forneceram como alimento exclusivo para ovinos (sem padrão racial definido) um subproduto composto de casca e semente desidratada de melão e observaram consumo de 1.157,5 g/dia de MS. O menor consumo de MS obtido nesta pesquisa pode ser atribuído ao aumento do volumoso na dieta e, consequentemente, ao maior conteúdo de fibra em detergente neutro (FDN) presente nas dietas (Tabela 2).

Esses resultados também permitem supor que, nos níveis de 60 e $100 \%$ de fruto-refugo de melão na dieta, o consumo de alimentos tenha sido limitado pelo enchimento, tendo em vista a maior quantidade de FDN. Por outro lado, nos níveis de 0 e $30 \%$, que possuíam acima de 50\% de concentrado, o consumo possivelmente foi controlado pela demanda energética do animal (Van Soest, 1994). Kozloski et al. (2006) e Cardoso et al. (2006), em pesquisas com os mesmos níveis de FDN (25, 31, 37 e 43\%) na dieta de cordeiros, observaram que o consumo de MS decresceu linearmente com o aumento do conteúdo de FDN.

Ellis (1978) relatou que dietas caracterizadas por elevada proporção de fibra influenciam o consumo, pelas características peculiares do trato digestivo dos ruminantes, com períodos longos de permanência do alimento e grande capacidade física de armazenamento do pré-estômago.

Tabela 3 - Consumo de nutrientes por ovinos Morada Nova em função dos níveis de melão nas dietas

\begin{tabular}{|c|c|c|c|c|c|c|c|}
\hline & \multicolumn{4}{|c|}{ Nível de melão, \% } & \multirow[t]{2}{*}{$\mathrm{CV}, \%$} & \multirow[t]{2}{*}{ Equação de regressão } & \multirow[t]{2}{*}{$\mathrm{R}^{2}$} \\
\hline & 0 & 30 & 60 & & & & \\
\hline \multicolumn{8}{|c|}{ Matéria seca, g/dia } \\
\hline Fêmea & 722 & 806 & 806 & 837 & 6,68 & $Y=721,10+4,5014-0,0523 x^{2}$ & 0,74 \\
\hline \multicolumn{8}{|c|}{ Matéria seca, \%PV } \\
\hline Macho & 2,89 & 3,19 & 3,51 & 646 & 7,88 & $Y=2,88+0,0157 x-0,0001 x^{2}$ & 0,96 \\
\hline \multicolumn{8}{|c|}{ Matéria seca, $\mathrm{kgPV}^{0,75} / \mathrm{dia}$} \\
\hline Macho & 70,97 & 70,00 & 72,09 & 2,75 & 20,19 & $\mathrm{Y}=70,24^{\mathrm{ns}}$ & 0,95 \\
\hline Fêmea & 69,27 & 60,34 & 45,06 & 67,90 & 20,19 & $Y=68,50-0,3182 x$ & \\
\hline \multicolumn{8}{|c|}{ Matéria orgânica, g } \\
\hline Macho & 716 & 780 & 858 & 752 & 6,64 & $Y=706,69+4,5501 x-0,0403 x^{2}$ & 0,86 \\
\hline Fêmea & 672 & 745 & 739 & 582 & 6,64 & $Y=671,26+4,0459 x-0,0493 x^{2}$ & 0,95 \\
\hline \multicolumn{8}{|c|}{ Proteína bruta, g } \\
\hline \multicolumn{8}{|c|}{ Extrato etéreo, g } \\
\hline Macho & 18 & 24 & 30 & 33 & 7,33 & $Y=18+0,2614 x-0,0011 x^{2}$ & 0,98 \\
\hline Fêmea & 17 & 23 & 26 & 25 & 7,33 & $Y=17+0,2476 x-0,0017 x^{2}$ & 0,94 \\
\hline \multicolumn{8}{|c|}{ Fibra em detergente neutro, g } \\
\hline Macho & 313 & 360 & 416 & 394 & 6,84 & $Y=309+2,6903 x-0,0181 x^{2}$ & 0,94 \\
\hline Fêmea & 294 & 343 & 360 & 305 & 6,84 & $Y=294+2,4662 x-0,0235 x^{2}$ & 0,98 \\
\hline \multicolumn{8}{|c|}{ Nutrientes digestíveis totais, g } \\
\hline Macho & 629 & 695 & 785 & 695 & 7,96 & $Y=619+4,6489 x-0,0383 x^{2}$ & 0,87 \\
\hline Fêmea & 597 & 671 & 657 & 518 & 7,96 & $Y=598+3,777 x-0,0461 x^{2}$ & 0,95 \\
\hline \multicolumn{8}{|c|}{ Carboidratos totais, g } \\
\hline
\end{tabular}

Significativo a $5 \%$ de probabilidade pelo teste $\mathrm{t}$.

ns - não-significativo; CV e $\mathrm{R}^{2}$ - coeficiente de variação e determinação, respectivamente. 
Assim, o mecanismo que regula o consumo, a distensão ruminal, é influenciado pelas taxas de digestão e de passagem do alimento.

Além desses fatores, a inclusão de maior quantidade do fruto de melão pode ter favorecido a fermentação da ração no cocho, o que pode ter provocado restrição da ingestão voluntária dos animais. Segundo Teixeira \& Teixeira (1998), a ingestão de MS pode reduzir quando ocorre aquecimento, putrefação e mofo em alimentos ensilados ou na ração total.

Entre os machos, o consumo de MS por unidade de peso metabólico nos níveis 0 , 30, 60 e 100 de melão em substituição ao milho moído foi de 70,97; 70,00; 72,09 e $67,90 \mathrm{gMS} / \mathrm{PV}^{0,75}$. O NRC (1985) estabelece que o consumo de MS por unidade de peso metabólico (g MS/PV ${ }^{0,75}$ ) para animais com $20 \mathrm{~kg}$ de peso vivo seria em torno de 105,7 g/dia. Lousada Júnior et al. (2005) observaram para o consumo de MS por unidade de peso metabólico valor médio de $83 \mathrm{gMS} / \mathrm{PV}^{0,75}$, para ovinos sem padrão racial definido (SPRD) recebendo dieta exclusiva com o subproduto de melão (casca e semente desidratada).

Tanto nos animais machos como nas fêmeas, houve efeito quadrático dos níveis de melão na dieta sobre os consumos de matéria orgânica, proteína bruta, extrato etéreo, fibra em detergente neutro, nutrientes digestíveis totais, carboidratos totais e carboidratos não-fibrosos, refletindo o mesmo comportamento verificado para a ingestão de MS, em g/dia. O menor consumo de MO, NDT e carboidratos pode ser explicado pela baixa participação desses componentes nas dietas, que foi menor para as dietas com maiores porcentagens de frutos-refugo de melão.

Os valores de 1,23; 1,32; 1,53 e 1,49\% para o consumo de FDN em relação \% PV neste trabalho foram superiores aos citados por Van Soest (1994), que sugeriu consumo de FDN entre 0,80 e 1,20\% do PV. A ingestão da FDN em $\mathrm{g} /$ animal/dia foi inferior à mencionada por Dantas Filho et al . (2007), que obtiveram valores de 576, 635, 700 e $796 \mathrm{~g}$ utilizando níveis de $0,10,20,3040 \%$ de polpa de caju desidratada na alimentação de ovinos.

O consumo de NDT, assim como de outros nutrientes, apresentou comportamento quadrático em resposta à substituição do milho moído por melão (Tabela 3). Este comportamento para o consumo de NDT provavelmente se deve ao valor decrescente de NDT na MS da dieta. Os consumos de NDT nos níveis de 30, 60 e 100\% de substituição do milho por melão foram superiores ao recomendado pelo NRC (1985), que é de $600 \mathrm{~g} / \mathrm{dia}$ para ganho de peso de 150 g/dia.

Entre os machos, o consumo de proteína bruta (CPB) foi de 125, 139, 158 e $140 \mathrm{~g} /$ dia e, entre as fêmeas, 117, 133, 136 e $108 \mathrm{~g} /$ dia. O consumo de PB apresentou comportamento quadrático em resposta aos níveis de melão, apesar de as dietas serem isoproteicas. Os níveis de melão tiveram efeito quadrático sobre consumo de extrato etéreo (EE) foi, alcançando o valor máximo de $33 \mathrm{~g} /$ dia e de $26 \mathrm{~g}$ /dia para os machos e as fêmeas, respectivamente. Este comportamento para o consumo de EE provavelmente ocorreu pelo aumento na participação de torta de algodão e do melão, que continham 9,60\% e 7,62\% de EE (Tabela 1), respectivamente, o que proporcionou maior incremento desse nutriente nas dietas. Lousada Junior et al. (2005) avaliaram o consumo e a digestibilidade aparente de subprodutos da agroindústria e encontraram na análise bromatológica do subproduto do melão (casca e semente) valor de 3,3 g de extrato etéreo.

Para o consumo da FDN, verificou-se efeito quadrático para ambos os sexos, com consumo de 313, 360, 416 e 394 g para os machos e de 294, 343, 360 e 305 g para as fêmeas, à medida que o teor de fruto-refugo de melão aumentava nas dietas. Este consumo da FDN pode ser explicado pela ingestão de MS, que apresentou comportamento quadrático. Resultado semelhante aos encontrados por Dias et al., (2000), Véras et al., (2000), Barreto et al., (2004), Kozloski et al. (2006) e Cardoso et al., (2006), que verificaram aumento no consumo de FDN à medida que aumentaram o teor de FDN na dieta.

As dietas continham, em média, 30,41; 28,79; 27,11 e 24,86\% de carboidratos não-fibrosos (CNF) na MS (Tabela 2). Esta menor concentração deste nutriente a $100 \%$ de substituição justifica os menores consumos observados na Tabela 3.

A digestibilidade aparente da MS apresentou comportamento linear decrescente à medida que aumentou a participação do fruto-refugo de melão na dieta em substituição ao milho moído. Este comportamento na digestibilidade da MS pode ser explicado pela elevação das concentrações de FDN e lignina nos níveis de substituições e pela menor participação de concentrado na dieta. Araújo et al. (1998), estudando o consumo e a digestibilidade total dos nutrientes de dietas contendo diferentes níveis de volumosos em bezerros, concluíram que o nível de volumoso na dieta influencia a digestibilidade aparente de MS, que decresceu linearmente com o aumento da porcentagem de volumoso.

O resultado encontrado para a digestibilidade aparente da MS para a dieta com a maior participação de melão está próximo do encontrado por Lousada Júnior et al. (2005) e Silva et al. (2005), que, pesquisando a influência da adição de melão na alimentação de ruminantes, encontraram valores de 47,75 e 56,41\% para a digestibilidade aparente, respectivamente. 
A digestibilidade aparente da $\mathrm{MO}$ aumentou linearmente com a inclusão do fruto-refugo de melão na dieta, resultado que difere do encontrado por Rode et al. (1985) e Bürger et al. (2000), que utilizaram diferentes níveis de volumoso na dieta e observaram que a redução do nível de volumoso foi acompanhada pelo aumento da digestibilidade aparente da MS e MO. Bourquini et al. (1994) obtiveram maiores coeficientes de digestibilidade da MO, para rações com menores percentagens de carboidrato estrutural. Provavelmente este aumento linear na digestibilidade aparente da MO ocorreu em virtude de os animais terem selecionado o frutorefugo de melão e o concentrado (torta de algodão e farelo de soja), alimentos que possuem maior teor de carboidratos não-estruturais em detrimento do feno de capim-elefante rico em carboidratos estruturais.

Com relação à digestibilidade aparente da PB, verificou-se efeito linear crescente da inclusão de melão na dieta. Possivelmente esse aumento ocorreu em função da maior ingestão do fruto-refugo de melão, cuja digestibilidade aparente da proteína bruta é de 65\% (Lousada Júnior et al., 2005).

O coeficiente da digestibilidade aparente do extrato etéreo foi influenciado pela inclusão de melão na dieta apresentado efeito linear crescente (Tabela 4). Houve um aumento no teor de extrato etéreo (2,40; 2,83; 3,28 e 3,92\%) nas rações, devido à maior quantidade de sementes presentes no melão (Tabela 2) e pelo aumento da participação da torta de algodão, que tem 9,60\% de EE na sua composição.

$\mathrm{O}$ aumento linear do coeficiente de digestibilidade aparente da FDN pode ter sido influenciado pelos níveis de volumosos nas dietas, que também apresentaram maiores teores de FDN em suas composições totais. Outros autores também observaram efeito do nível de FDN sobre o coeficiente de digestibilidade aparente da FDN (Cassida et al., 1994, Bürger et al., 2000; Mizubuti et al., 2002).

O coeficiente de digestibilidade dos carboidratos nãofibrosos não foi influenciado pelos níveis do fruto-refugo de melão na ração e apresentou valor médio de 95\%, próximo àquele apresentado por Silva et al. (2005), que avaliaram a substituição do farelo de trigo por melão na dieta de vacas de leite e observaram coeficiente de digestibilidade aparente dos CNF de $82 \%$ com nível de substituição de $26 \%$.

Houve efeito linear decrescente da participação de melão na dietas sobre o ganho de peso diário. O sexo também teve efeito sobre o ganho de peso diário, pois os ganhos foram maiores nos machos (163, 147, 150 e $133 \mathrm{~g} / \mathrm{dia})$ em relação às fêmeas (115, 110, 91 e 73 g/dia). O tempo de permanência dos animais no confinamento $(79,78,89$, 91dias) aumentou linearmente $(\mathrm{P}<0,05)$ à medida que se ofertou maior quantidade do fruto refugo de melão na dieta dos animais elevando o número de dias de confinamento com o menor ganho de peso diário pelos animais que receberam maior participação de melão. A maior permanência no confinamento aumenta a idade ao abate, diminui a rotatividade de animais no confinamento, desfavorece a qualidade da carcaça, devido à maior deposição de gordura na carcaça, e também eleva os custos de produção.

Os maiores ganhos de peso observados com os machos são semelhantes aos divulgados por Figueiró \& Benavides (1990), quando afirmaram que machos não castrados têm velocidade de crescimento maior que a dos castrados e estes maiores que das fêmeas. De acordo com Jacobs et al. (1972), o crescimento em machos não-castrados é atribuído à produção de testoterona, que é responsável pelo aumento na eficiência alimentar e promotora do crescimento muscular e esquelético.

Resultados aproximados foram encontrados por Jenkins et al. (1988), que observaram ganho diário de 340, 298 e 270 g para machos não-castrados, castrados e fêmeas, respectivamente, submetidos às mesmas condições alimentares e por Carvalho et al. (1999), que avaliaram o desempenho de cordeiros machos inteiros, machos castrados e fêmeas, alimentados em confinamento. Estes autores verificaram ganhos diário de 316, 313 g e 299 g para machos não-castrados, castrados e fêmeas respectivamente.

A conversão alimentar da MS não sofreu efeito $(\mathrm{P}>0,05)$ da substituição do milho por melão (Tabela 5). Entretanto, os machos apresentaram melhor eficiência em relação às fêmeas, comprovando possível eficiência de utilização do

Tabela 4 - Coeficiente de digestibilidade aparente dos nutrientes por ovinos Morada Nova em função dos níveis de melão nas dietas

\begin{tabular}{|c|c|c|c|c|c|c|c|}
\hline \multirow[b]{2}{*}{ Variável } & \multicolumn{4}{|c|}{ Nível de melão, \% } & \multirow[b]{2}{*}{$\mathrm{CV}, \%$} & \multirow[b]{2}{*}{ Equação de regressão } & \multirow[b]{2}{*}{$\mathrm{R}^{2}$} \\
\hline & 0 & 30 & 60 & 100 & & & \\
\hline Matéria seca, \% & 80,11 & 54,77 & 64,17 & 49,66 & 16,54 & $Y=74-0,2474 x$ & 0,63 \\
\hline Proteína bruta, \% & 84,40 & 84,72 & 92,95 & 93,65 & 2,51 & $Y=84+0,1072 x$ & 0,82 \\
\hline Extrato etéreo, \% & 70,94 & 64,83 & 82,19 & 84,48 & 8,64 & $Y=67+0,1751 x$ & 0,69 \\
\hline Fibra em detergente neutro, \% & 33,68 & 32,65 & 61,64 & 65,00 & 20,60 & $Y=31+0,3636 x$ & 0,77 \\
\hline
\end{tabular}

Significativo a $5 \%$ de probabilidade pelo teste $t$.

ns - não-significativo; CV e $\mathrm{R}^{2}$ - coeficiente de variação e determinação, respectivamente. 
Tabela 5 - Desempenho de ovinos Morada Nova em função dos níveis de substituição do milho moído por melão na dieta

\begin{tabular}{|c|c|c|c|c|c|c|c|}
\hline \multirow[b]{2}{*}{ Variável } & \multicolumn{4}{|c|}{ Nível de melão, \% } & \multirow[b]{2}{*}{$\mathrm{CV}, \%$} & \multirow[b]{2}{*}{ Equação de regressão } & \multirow[b]{2}{*}{$\mathrm{R}^{2}$} \\
\hline & 0 & 30 & 60 & 100 & & & \\
\hline PV inicial & 15,24 & 15,73 & 15,27 & 15,21 & 9,63 & $Y=15,36$ & - \\
\hline \multicolumn{8}{|l|}{ Ganho de peso diário, g } \\
\hline Macho & 163 & 147 & 150 & 133 & 15,86 & $Y=161-0,0003 x$ & 0,85 \\
\hline Fêmeas & 115 & 110 & 91 & 73 & 15,86 & $Y=118,74-0,0004 x$ & 0,97 \\
\hline Fêmea & 7,31 & 7,69 & 8,17 & 9,43 & 19,02 & $Y=8,27$ & \\
\hline Eficiência alimentar, \% & 17,43 & 16,18 & 16,63 & 16,41 & 18,33 & $Y=16,66$ & \\
\hline Macho & 17,99 & 17,77 & 19,28 & 17,94 & 18,33 & $\mathrm{Y}=18,24$ & \\
\hline Fêmea & 16,50 & 13,54 & 12,22 & 13,85 & 18,33 & $Y=14,03$ & \\
\hline
\end{tabular}

Significativo a $5 \%$ de probabilidade pelo teste de t.

ns - não-significativo; $\mathrm{CV}$ e $\mathrm{R}^{2}$ - coeficiente de variação e determinação, respectivamente.

PV - peso vivo; MS - matéria seca; GPD - ganho de peso diário.

alimento pelos machos inteiros, resultados que estão de acordo com os encontrados Field (1971), de que cordeiros não-castrados são 12 a 15\% mais eficientes em ganho de peso vivo.

\section{Conclusões}

O fornecimento de dietas contendo melão em substituição ao milho o diminui linearmente o ganho de peso de ovinos Morada Nova em confinamentos. Em níveis acima de $60 \%$ de substituição, diminui o consumo de nutrientes e aumenta os dias de confinamento, elevando a idade ao abate.

\section{Referências}

AGRiAnUAl. Anuário da agricultura brasileira. São Paulo: Instituto FNP, 2010. p.400.

ARAÚJO, G.G.L.; SILVA, J.F.C.; VALADARES FILHO, S.C. et al. Consumo e digestibilidade total dos nutrientes de dietas contendo diferentes níveis de volumoso, em bezerros. Revista Brasileira de Zootecnia, v.27, n.2, p.345-354, 1998.

BARRETO, C.M.; AZEVEDO, A.R.; SALES, R.O. et al. Desempenho de ovinos alimentados com dietas contendo diferentes níveis de dejetos de suínos. Revista Brasileira de Zootecnia, v33, n.6, p.1858-1865, 2004.

BERCHIELLI, T.T.; ANDRADE, P.; FURLAN, C.L. Avaliação de indicadores internos em ensaios de digestibilidade. Revista Brasileira de Zootecnia, v.29, n.3, p.830-833, 2000.

BOURQUIN, L.D.; TIGEMEYER, E.C.; MERCHEN, N.R. et al. Forage level and particle size effects on orchardgrass digestion by steers: I Site and extent of organic matter, nitrogen, and cell wall digestion. Journal of Animal Science, v.72, p.746-758, 1994.

BÜRGER, P.J.; PEREIRA, J.C.; COELHO DA SILVA, J.F. et al. Consumo e digestibilidade aparente total e parcial em bezerros holandeses alimentados com dietas contendo diferentes níveis de concentrado. Revista Brasileira de Zootecnia, v.29, p.206-214, 2000.

CARDOSO, R.A.; PIRES, C.C.; CARVALHO, S. et al. Consumo de nutrientes e desempenho de cordeiros alimentados com dietas que contêm diferente níveis de fibra em detergente neutro. Ciência Rural, v.36, n.1, p.215-221, 2006.
CASSIDA, K.A.; BARTON, B.A.; HOUGH, R.L. et al. Feed intake and apparent digestibility of hay-supplemented brassica diets for lambs. Journal of Animal Science, v.72, p.1623-1629, 1994.

CARVALHO, S.; PIRES, C.C.; PERES, J.R.R. et al. Desempenho de cordeiros machos inteiros, machos castrados e fêmeas, alimentados em confinamento. Ciência Rural, v.29, n.1, p.129-133, 1999.

DANTAS FILHO, L.A.; LOPES, J.B.; VASCONCELOS, V.R. Inclusão de polpa de caju desidratada na alimentação de ovinos: desempenho, digestibilidade e balanço de nitrogênio. Revista Brasileira de Zootecnia, v.36, n.1, p.147-154, 2007.

DHAKAD, A.; GARG, A.K.; SIHGH, P. Effect of replacement of maize grain with wheat bran on the performance of growing lambs. Small Ruminant Research, v.43, p.227-234, 2002.

DIAS, H.L.C.; VALADARES FILHO, S.C.; COELHO DA SILVA, J.F. et al. Consumo e digestão totais e parciais em novilhos F1 Limousin x Nelore alimentados com dietas contendo cinco níveis de concentrado. Revista Brasileira de Zootecnia, v.29, n.2, p.545-554, 2000.

ELLIS, W.C. Determination of grazed forage intake and digestibility. Journal Dairy Science, v.61, n.12, p.1828-1840, 1978.

FIGUEIRÓ, P.R.P.; BENAVIDES, M.V. Produção de carne ovina. In: Simpósio sobre produção animal, 7, 1990. Campinas, SP. Anais... Piracicaba. SP. FEALQ, p.171 - 187, 245p.

FIELD, R.A. Effect of castration on meat quality and quantity. Journal of Animal Science, v.32, n.5, p.849-858, 1971.

JACOBS, J.A.; FIELD, R.A.; BOTKIN, M.P. et al. Effects of testosterone enanthate on lambs carcass composition and quality. Journal of Animal Science, v.34, p.30, 1972.

JENKINS, T.G.; FORD, J.J.; KLINDT, J. Postweaning growth, feed efficiency and chemical composition of sheep as affected by prenatal and postnatal testosterone. Journal of Animal Science, v.66, p.1179-1185, 1988.

KOZLOSKI, G.V.; TREVISAN, L.M.; BANNECARRE, L.M. et al. Níveis de fibra em detergente neutro na dieta de cordeiros: consumo, digestibilidade e fermentação ruminal. Arquivo Brasileiro de Medicina Veterinária e Zootecnia, v.58, n.5, p.893-900, 2006.

LOUSADA JUNIOR, J.E.J.; NEIVA, J.N.M.; RODRIGUEZ, N.M. et al. Consumo e digestibilidade de subprodutos do processamento de frutas em ovinos. Revista Brasileira de Zootecnia, v.34, p.659-669, 2005.

MANTEROLA, B.; CERDA, A.; FORTE, F. et al. Valor nutritivo y uso de resíduos hortifruticulas y agroindustriales en alimentación de ruminantes. SIMPOSIO SOBRE UTILIZAÇÃO DE SUBPRODUTOS E RESÍDUOS DE COLHEITAS NA ALIMENTAÇÃO DE RUMINANTES. 1992, São Carlos. Anais... Embrapa/Uepae, 1992. p.297-324. 
MIZUBUTI, I.Y.; KHATOUNIAN, C.A.; RIBEIRO, E.L.A. et al. Consumo médio e digestibilidade aparente dos nutrientes do feno de aveia e ervilha em ovinos submetidos a dois regimes alimentares. Revista Brasileira de Zootecnia, v.31, n.2, p.1042-1049, 2002.

NATIONAL RESEARCH COUNCIL - NRC. Nutrient requirements of sheep. National Academy Press. Washington, 1985. 99p.

NATIONAL RESEARCH COUNCIL - NRC. Nutrient requirements of beef cattle. 7.rev.ed. Washington, D.C.: National Academic Press, 2000. 242p.

RODE, L.M.; WEAKLEY, D.C.; SATTER, L.D. Effect of forage amount and particle size in diets of lactating dairy cows on site of digestion and microbial synthesis. Journal of Animal Science, v.65, p.101-111, 1985.

SILVA, J.G.M.; LIMA, G.F.C.; MELO, A.A.S. et al. Utilização de fruto-refugo de melão em substituição ao farelo de trigo na alimentação de vacas leiteiras. 3 - Digestibilidade. 42 Reunião Anual da Sociedade Brasileira de Zootecnia. Goiânia. Anais...SBZ, 2005. CD-ROM.

SILVA, D.J.; QUEIROZ, A.C. Análise de alimentos: métodos químicos e biológicos. Viçosa, MG: UFV, 2002. 235p.
SNIFFENL, C.J.; O’CONNOR, J.D.; VAN SOEST, P.J. et al. A net carbohydrate and protein system for evaluating diets. II. Carbohydrate and protein availability. Journal of Animal Science, v.70, p.3562-3577, 1992.

TEIXEIRA, J.C.; TEIXEIRA, L.F.A.C. Do alimento ao leite: entenda a função do rúmen. Lavras: UFLA - FAEPE, 1998. 72p.

VAN SOEST, P.J.; ROBERTSON, J.B.; LEWIS, B.A. Symposium: carbohydrate methodology, metabolism, and nutritional implications in dairy cattle. Journal of Dairy Science, v.74, n.10, p.3583-3597, 1991.

VAN SOEST, P.J. Nutritional ecology of the ruminant. 2.ed. Ithaca: Cornell University Press, 1994. 476p.

VÉRAS, A.S.C.; VALADARES FILHO, S.C.; COELHO DA SILVA, J.F. et al. Consumo e digestibilidade aparente em bovinos Nelore, não-castrados, alimentados com rações contendo diferentes níveis de concentrado. Revista Brasileira de Zootecnia, v.29, p.2367-2378, 2000 (supl. 2).

WEISS, W.P. Energy prediction equations for ruminant feeds. In: CORNELL NUTRITION CONFERENCE FOR FEED MANUFACTURERS, 61., 1999. Proceeding... Ithaca: Cornell University, 1999. p.176-185. 